Springer-Verlag Wien GmbH 


\author{
Gerhard Wachutka \\ Gabriele Schrag (eds.)
}

\title{
Simulation of Semiconductor Processes and Devices \\ 2004
}

SISPAD 2004 


\author{
Dr. Gerhard Wachutka \\ Dr. Gabriele Schrag \\ Lehrstuhl für Technische Elektrophysik \\ Technische Universität München \\ Munich, Federal Republic of Germany
}

This work is subject to copyright.

All rights are reserved, whether the whole or part of the material is concerned, specifically those of translation, reprinting, re-use of illustrations, broadcasting, reproduction by photocopying machines or similar means, and storage in data banks.

Product Liability: The publisher can give no guarantee for the information contained in this book. This also refers to that on drug dosage and application thereof. In each individual case the respective user must check the accuracy of the information given by consulting other pharmaceutical literature.

The use of registered names, trademarks, etc., in this publication does not imply, even in the absence of a specific statement, that such names are exempt from the relevant protective laws and regulations and therefore free for general use.

(C) 2004 Springer-Verlag Wien

Originally published by Springer- Verlag Wien New York in 2004

Softcover reprint of the hardcover 1st edition 2004

springeronline.com

Typesetting: Camera ready by authors

Printed on acid-free and chlorine-free bleached paper

SPIN 11301585

With 448 Figures and a CD-ROM

Additional material to this book can be downloaded from http://extra.springer.com

ISBN 978-3-7091-7212-4 ISBN 978-3-7091-0624-2 (eBook)

DOI 10.1007/978-3-7091-0624-2 


\section{Editorial}

This volume contains the proceedings of the $10^{\text {th }}$ edition of the International Conference on Simulation of Semiconductor Processes and Devices (SISPAD 2004), held in Munich, Germany, on September 2-4, 2004. The SISPAD conference is annually organized, with alternating venues in Europe, Japan, and North America. SISPAD 2002 took place in Kobe, Japan, and SISPAD 2003 was held in Boston, MA, USA. This year's SISPAD was organized by the Institute for Physics of Electrotechnology, Munich University of Technology.

Like the previous meetings, SISPAD 2004 provided a world-wide forum for the presentation and discussion of recent advances and developments in the theoretical description, physical modeling and numerical simulation and analysis of semiconductor fabrication processes, device operation and system performance. The variety of topics covered by the conference contributions reflects the physical effects and technological problems encountered in consequence of the progressively shrinking device dimensions and the ever-growing complexity in device technology. The rapid progress made in this field necessitates continuous advances in the physical models and simulation tools, which constitute the basis for predictive simulation on all descriptive levels from atomistic models up to full system macromodels, as they are offered by state-of-the-art TCAD platforms.

The conference program included 7 invited plenary lectures and 82 contributed papers for oral or poster presentation, which were carefully selected out of a total of 151 abstracts submitted from 14 countries around the world.

The proceedings volume contains eight-page manuscripts as received from the invited authors and four-page extended abstracts of the contributed papers. All of them were reproduced as submitted, and therefore the responsibility for the contents rests exclusively with the authors. We express our sincere appreciation to them for respecting the guidelines and for their effort to provide high-quality contributions.

The editors wish to thank the members of the Technical Program Committee for proposing the invited speakers and for the careful selection of the contributed papers. We gratefully acknowledge the support of all people who helped us to make SISPAD 2004 a success.

Gerhard Wachutka

Conference Chair
Gabriele Schrag

Technical Program Organization 


\section{Steering Committee}
K. De Meyer
J. Faricelli
M. Hane
P. Leon
N. Nakayama
S. Odanaka
P. Oldiges
D. Tsoukalas
G. Wachutka

R. Dutton

S. Selberherr

K. Taniguchi

D. Donoval

S. Dunham

T. Feudel

N. Goldsman

M. Hane

A. Heringa

H. Jaouen

S. Jones

J.-T. Kong

P. Leon

J. Lorenz

K. Mayaram

M. Miura-Mattausch

W. Molzer

Y. Oda

Y. Ohkura

P. Oldiges

M. Orlowski

M. Rudan

A. Schenk

W. Schoenmaker

S. Selberherr

D. Tsoukalas

C.-C. Wang
IMEC

Compaq

NEC Corporation

Nanosys, Inc.

STARC

Osaka University

IBM Corporation

NCSR 'Demokritos'

Munich University of Technology

\section{Honorary Committee}

Stanford University

TU Vienna

Osaka University

USA

Austria

Japan

\section{Technical Program Committee}

Slovak Technical University

University of Washington

AMD Saxony LLC \& Co. KG

University of Maryland

NEC Corporation

Philips Research Lab. Leuven

ST Microelectronics

Bookham Technologies

Samsung Electronics

Nanosys, Inc.

Fraunhofer IISB

Oregon State University

Hiroshima University

Infineon Technologies Munich

Matsushita Electric Industrial Co.

SELETE

IBM Corporation

Belgium

USA

Japan

USA

Japan

Japan

USA

Greece

Germany
Motorola Inc.

University of Bologna

ETH Zürich

Magwel NV

TU Vienna

NCSR 'Demokritos'

TSMC
Slovakia

USA

Germany

USA

Japan

The Netherlands

France

U.K.

Korea

USA

Germany

USA

Japan

Germany

Japan

Japan

USA

USA

Italy

Schwitzerland

Belgium

Austria

Greece

Taiwan 


\section{Contents}

Grasser, T., Jungemann, C., Kosina, H., Meinerzhagen, B., Selberherr, S.

Advanced Transport Models for Sub-Micrometer Devices

Klimeck, $G$.

NEMO-1D: the First NEGF-Based TCAD Tool

Rudan, M., Gnani, E., Reggiani, S., Baccarani, G.

The Density-Gradient Correction as a Disguised Pilot Wave of de Broglie ....

Esseni, D., Palestri, $P$.

Full Band and Approximated Solutions of the Schrödinger Equation

in Silicon Inversion Layers

Shao, $X ., Y u, Z$.

A Hybrid 3D Quantum Mechanical Simulation of FinFETs and

Nanowire Devices

Gehring, A., Selberherr, S.

On the Calculation of Quasi-Bound States and Their Impact on

Direct Tunneling in CMOS Devices

Ogawa, M., Kagotani, N., Ohta M., Miyoshi, T.

Quantum Mechanical Simulation in DG MOSFETs Based on a

Tight Binding Green's Function Formalism

Radic, L., Saavedra, A. F., Law, M. E.

Modeling B Uphill Diffusion in the Presence of $\mathrm{Ge}$

Diebel, M., Chakravarthi, S., Dunham, S. T., Machala, C. F.

Ab-initio Calculations To Predict Stress Effects on Boron Solubility

in Silicon

Wang, C. C., Huang, T. Y., Sheu, Y. M., Duffy, R., Heringa, A.,

Cowern, N. E. B., Griffin, P. B., Diaz, C. H.

Boron Diffusion in Strained and Strain-Relaxed SiGe

Pakfar, A., Holliger, P., Poncet, A., Fellous, C., Dutartre, D., Schwartzmann, T., Jaouen, $H$.

Modeling Dopant Diffusion in SiGe and SiGeC layers

Chakravarthi, S., Chidambaram, P. R., Hornung B., Machala, C. F.

Continuum Modeling of Indium To Predict SSR Profiles

Ezaki, T., Nakamura, H., Yamamoto, T., Takeuchi, K., Hane, M.

Theoretical Analysis of Stress and Surface Orientation Effects on

Inversion Carrier Mobility

Chang, L., Ieong, M., Yang, $M$.

CMOS Circuit Performance Enhancement by Surface Orientation

Optimization

Fujii, O., Yoshimura, H., Hasumi, R., Sanuki, T., Oyamatsu, H., Matsuoka, F.,

Noguchi, $T$.

Modeling of Stress Induced Layout Effect on Electrical Characteristics

of Advanced MOSFETs

Wang, X., Shang, H., Oldiges, P., Rim, K., Koester, S., Ieong, M.

Hole Mobility Enhancement Modeling and Scaling Study for

High Performance Strained Ge Buried Channel PMOSFETs 
Li, J., Hull, R., Yang, R., Hou, V., Mouli, C.

Three-Dimensional Characterization and Modelling of Stress Distribution in High-Density DRAM Memory Cells

Kanegae, Y., Moriya, H., Iwasaki, T.

Strain Optimization To Reduce Gate Leakage Current in MOS Transistors

with Silicon Oxynitride Gate Dielectrics by Use of First-Principles

Calculations

Ouyang, Q., Ning, T. H.

Simulation Study of Simple CMOS-Compatible Thin-SOI Vertical

Bipolar Transistors on Thin BOX with an Inversion Collector

Sleiman, A., Di Carlo, A., Verzellesi, G., Meneghesso, G., Zanoni, E.

Current Collapse Associated with Surface States in GaN-Based HEMT's.

Theoretical/Experimental Investigations

Krivokapic, Z., Moroz, V.

Implications of Gate Misalignment for Ultra-Narrow Multi-Gate Devices ....

Lorenzini, M., Wellekens, D., Haspeslagh, L., Van Houdt, J.

Source-Side Injection Modeling by Means of the

Spherical-Harmonics Expansion of the BTE

Wang, P.-F., Nirschl, T., Schmitt-Landsiedel, D., Hansch, W.

Investigation of a Novel Tunneling Transistor by MEDICI Simulation

Thalhammer, R., Marksteiner, $S$.

Optimization of BAW Resonator Performance Using Combined

Simulation Techniques

Piprek, J.

Simulation of GaN-Based Light-Emitting Devices

Grasser, T., Kosina, H., Selberherr, $S$.

On the Validity of the Relaxation Time Approximation for Macroscopic

Transport Models

Schenk, A.

A Local Mobility Model for Ultra-Thin DGSOI nMOSFETs

Nayfeh, O. M., Yu, S., Antoniadis, D. A.

On the Relationship between Carrier Mobility and Velocity in Sub-50 nm

MOSFETs via Calibrated Monte Carlo Simulation

Rudan, M., Perroni, G.

A Method for Determining the Screening Length of the Coulombic

Scattering in Non-Degenerate and Degenerate Semiconductors

Burenkov, A., Lorenz, J.

3D Simulation of Process Effects Limiting FinFET Performance

and Scalability

Hössinger, A., Minixhofer, R., Selberherr, S.

Full Three-Dimensional Analysis of a Non-Volatile Memory Cell

Horn, A., Wachutka, G.

Three-Dimensional Simulation of Orientation-Dependent Wet

Chemical Etching

Jacobs, W., Kersch, A., Prechtl, G., Schulze Icking-Konert, G.

Modeling CVD effects in Atomic Layer Deposition on the Feature Scale 
Miyamoto, $Y$.

Defect and Carrier Dynamics in Nanotubes under Electronic Excitations:

Time-Dependent Density Functional Approaches

Pourfath, M., Ungersboeck, E., Gehring, A., Cheong, B. H., Kosina, H., Selberherr, $S$.

Three-Dimensional Analysis of Schottky Barrier Carbon Nanotube

Field Effect Transistors

Akturk, A., Pennington, G., Goldsman, N.

Numerical Performance Analysis of Carbon Nanotube (CNT) Embedded

MOSFETs

Ruhstaller, B., Beierlein, T. A., Gmür, R., Karg, S., Riel, H., Sartoris, G.,

Schwarzenbach, H., Riess, W.

Parameter Extraction and Validation of an Electronic and Optical Model

for Organic Light-Emitting Devices

Nguyen, P.-H., Burenkov, A., Lorenz, J.

Adaptive Surface Triangulations for 3D Process Simulation

Wessner, W., Hollauer, C., Hössinger, A., Selberherr, $S$.

Anisotropic Laplace Refinement for Three-Dimensional Oxidation

Simulation

Wittmann, R., Hössinger, A., Selberherr, S.

Monte Carlo Simulation of Ion Implantation in Silicon-Germanium Alloys ..

Ishihara, T., Koga, J., Takagi, S.

Comprehensive Understanding of Carrier Mobility in MOSFETs with

Oxynitrides and Ultrathin Gate Oxides

Claeys, C., Simoen, E.

Physics and Modeling of Radiation Effects in Advanced

CMOS Technology Nodes

Krishnamohan, T., Jungemann, C., Saraswat, K. C.

Very High Performance, Sub-20 nm, Strained Si and $\mathrm{Si}_{\mathrm{x}} \mathrm{Ge}_{1-\mathrm{x}}$,

Hetero-Structure, Center Channel (CC) NMOS and PMOS DGFETs

Bufler, F. M., Schenk, A., Fichtner, W.

Scalability of FinFETs and Unstrained-Si/Strained-Si FDSOI-MOSFETs

Yang, L., Watling, J. R., Asenov, A., Barker, J. R., Roy, S.

Device Performance in Conventional and Strained Si n-MOSFETs with

High- $\kappa$ Gate Stacks

Choudhary, D., Catherwood, J., Clancy, P., Murthy, C. S.

Understanding the Role of Strain in Si-Ge Devices

Chun, J.-H., Choi, C.-H., Dutton, R. W.

Electro-Thermal Simulations of Strained-Si MOSFETs under

ESD Conditions

Groos, G., Jensen, N., Denison, M., Stecher, M.

Simulation of the Cross-Coupling among Snap Back Devices under

Transient High Current Stress

Icaza Deckelmann, A., Wachutka, G., Krumrey, J., Hirler, F.

Simulation of the Failure Mechanism of Power DMOS Transistors under

Avalanche Stress 
Tosaka, Y., Satoh, S., Oka, $H$.

An Accurate and Comprehensive Soft Error Simulator NISES II

Alexander, C., Brown, A. R., Watling, J. R., Asenov, A.

Impact of Scattering on Random Dopant Induced Current Fluctuations in

Decanano MOSFETs

Andrei, P., Mayergoyz, I. D.

Analysis of Random Doping and Oxide Thickness Induced Fluctuations

in Nanoscale Semiconductor Devices through Poisson-Schrödinger

Computations

Matsuzawa, K., Sano, N.

Stable Simulation of Impurity Fluctuation for Contact Resistance and

Schottky Diodes

Jungemann, C., Neinhüs, B., Nguyen, C. D., Meinerzhagen, B.

Impact of the Floating Body Effect on Noise in SOI Devices Investigated

by Hydrodynamic Simulation

Oldiges, $P$., Murthy, $C$.

Examination of Spatial Frequency Dependence of Line Edge Roughness

on MOS Device Characteristics

Choi, M., Jia, C., Milor, L.

Simulation of Lithography-Caused Gate Length and Interconnect Linewidth

Variational Impact on Circuit Performance in Nanoscale

Semiconductor Manufacturing

Kim, S.-D., Johnson, J. B., Yuan, J., Woo, J. C. S.

Optimization of Recessed and Elevated Silicide Source/Drain Contact

Structure Using Physical Compact Resistance Modeling and Simulation

in Ultra-Thin Body SOI MOSFETs

Fuchs, E., Dollfus, P., Lecarval, G., Robilliart, E., Barraud, S., Villanueva, D.,

Jaouen, $H$.

A New Backscattering Model for Nano-MOSFET Compact Modeling

Sadachika, N., Uetsuji, Y., Kitamaru, D., Mattausch, H. J., Miura-Mattausch, M.,

Weiss, L., Feldmann, U., Baba, S.

Fully-Depleted SOI-MOSFET Model for Circuit Simulation and

Its Application to $1 / \mathrm{f}$ Noise Analysis

Navarro, D., Nakayama, N., Machida, K., Takeda, Y., Chiba, S., Ueno, H.,

Mattausch, H. J., Miura-Mattausch, M., Ohguro, T., Iizuka, T., Taguchi, M.,

Miyamoto, $S$.

Modeling of Carrier Transport Dynamics at GHz-Frequencies for

RF Circuit-Simulation

Akil, N., van Langevelde, R., Goarin, P., van Duuren, M., Slotboom, M.

SPICE-Compatible Macro Model for Split-Gate Compact NVM Cell with Various Gap Sizes

Le Royer, C., Le Carval, G., Sanquer, M.

SET Accurate Compact Model for SET-MOSFET Hybrid Circuit Simulation . 267

Zhang, D., Zhu, G., Zhang, H., Tian, L., Yu, Z.

2D Quantum Mechanical (QM) Charge Model and Its Application to

Ballistic Transport of Sub-50 nm Bulk Silicon MOSFETs 
Iannaccone, G., Curatola, G., Fiori, G.

Effective Bohm Quantum Potential for Device Simulators Based on

Drift-Diffusion and Energy Transport

Toyabe, $T$.

Single Ion and Multi Ion MOSFETs Simulation with

Density Gradient Model

Racko, J., Kudela, P., Donoval, D., Wachutka, G.

Modeling and Simulation of Combined Thermionic Emission-Tunneling

Current through Interfacial Isolation Layer

Mohrhof, J., Silber, D.

Experiments on Minority Carrier Diffusion in Silicon:

Contribution of Excitons

Watanabe, K., Hamada, T., Kotani, K., Teramoto, A., Sugawa, S., Ohmi, T.

Accurate Temperature Drift Model of MOSFETs Mobility for

Analog Circuits

Ayalew, T., Grasser, T., Kosina, H., Selberherr, S.

Accurate Modeling of Lattice Site-Dependent Ionization Level of

Impurities in $\alpha$-SiC Devices

Krivokapic, Z., Xiang, Q., Lin, M.-R.

Strain Scaling for Ultra Thin Silicon NMOS Devices

Tanabe, R., Ashizawa, Y., Oka, $H$.

CMOS Scaling Analysis Based on ITRS Roadmap by Three-dimensional

Mixed-Mode Device Simulation

Li, Y., Lee, J.-W., Chou, H.-M.

Comparison of Nanoscale Metal-Oxide-Semiconductor Field Effect

Transistors

Yamazaki, H., Sakuraba, H., Masuoka, F.

Numerical Analysis for the Structure Dependence on the Subthreshold Slope

of Floating Channel Type SGT(FC-SGT) Flash Memory

Jin, S., Yi, J.-H., Park, Y. J., Min, H. S.

A Monte-Carlo Method for Distribution of Standby Currents and Its

Application to DRAM Retention Time

Subba, N., Luning, S., Riccobene, C., Feudel, T., Wei, A., Horstmann, M.

Optimal Contact Placement in Partially Depleted SOI with Application to

Raised Source-Drain Structures

Bloomfield, M. O., Cale, T. S.

Simulation of Microstructure Formation during Thin Film Deposition

Uematsu, M., Kageshima, H., Shiraishi, K.

Effect of Stress on Pattern-Dependent Oxidation of Silicon Nanostructures ...

Ceric, H., Sabelka, R., Holzer, S., Wessner, W., Wagner, S., Grasser, T.,

Selberherr, $S$.

The Evolution of the Resistance and Current Density during

Electromigration

Sukharev, V., Choudhury, R., Park, C.W.

3-D Physically-Based Electromigration Simulation in

Copper-Low-K Interconnect 
Bär, E., Lorenz, J., Ryssel, $H$.

3D Feature-Scale Simulation of Sputter Etching with Coupling to

Equipment Simulation

Gnani, E., Ghidoni, F., Rudan, M.

Automatic Optimization Algorithm for a Direct 2D and 3D Mesh

Generation from the Layout Information

Fühner, T., Erdmann, A., Ortiz, C. J., Lorenz, J.

Genetic Algorithm for Optimization and Calibration in Process Simulation ... 347

Wagner, S., Grasser, T., Selberherr, S.

Performance Evaluation of Linear Solvers Employed for

Semiconductor Device Simulation

Matsuoka, F., Sakuraba, H., Masuoka, F.

An Analysis of the Effect of Surrounding Gate Structure on

Soft Error Immunity

Pethe, A., Krishnamohan, T., Uchida, K., Saraswat, K. C.

Analytical Modeling of Ge and Si Double-Gated (DG) NFETs and the

Effect of Process Induced Variations (PIV) on Device Performance

Mugnaini, G., Iannaccone, G.

Proposal of Physics-Based Compact Model for Nanoscale MOSFETs

Including the Transition from Drift-Diffusion to Ballistic Transport

Ito, C., Tornblad, $O$., Ma, G., Dutton, $R$. W.

A New Methodology for Efficient and Reliable Large-Signal Analysis of RF Power Devices

Jang, J., Dutton, $R$. W.

Small-Signal Modeling of RF CMOS 